\title{
Understanding the Digital and Non-digital Participation by the Gaming Youth
}

\author{
Iikka Pietilä ${ }^{(\varpi)}$, Jari Varsaluoma, and Kaisa Väänänen \\ Tampere University, Computing Sciences, Human-Centered Technology, Tampere, Finland \\ iikka.pietila@tuni.fi
}

\begin{abstract}
It is important for the inclusiveness of society that the youth actively participate in its development. Even though the means of digital participation have advanced in the past decade, there is still lack of understanding of digital participation of the youth. In this paper, we present a study on how youth aged 16-25 years perceive social and societal participation and more specifically, how youth currently participate in non-digitally and digitally. We conducted a mixed method study in a large gaming event in Finland using a questionnaire $(\mathrm{N}=277)$ and face-to-face interviews ( $\mathrm{N}=25)$. The findings reveal that the gaming youth consider digital participation to include discussions in different social media services or web discussion forums. Creating digital content (e.g. videos) and answering surveys were also emphasized. Perceived advantages to participate digitally include the freedom regarding location and time, ease and efficiency in sharing information, and inexpensiveness. Central disadvantages include lack of commitment, anonymity, misinformation and cheating. We also found that frequently playing gamers are more likely to participate online in social activities than those who play occasionally. Youth who reported that they play strategy games were more active in civic participation than those who do not play strategy games. We discuss the implications of our findings to the design of tools for digital participation.
\end{abstract}

Keywords: Youth, Gaming, Games, Digital participation, Societal participation.

\section{Introduction}

The participation of Finnish citizens has decreased significantly during the last three decades (Pessala, 2009; Myrskylä, 2012; Sutela et al., 2018). By lack of participation, we refer to people who do not participate in the processes of society, and people that are not employed or in education (Myrskylä, 2011). The Finnish National Institute for Health and Welfare (THL) (Isola et al., 2017) define participation ("osallisuus" in Finnish) to be 1) The ability to decide about one's own life and the possibility to regulate one's own doings, 2) engaging in processes that have effects in groups, services, living environments, and in the society, 3) local, when one is able to participate and contribute to the common good, and 4) to engage in creating meaningfulness and experience social relationships. Participation is also described to include the processes that the youth is able to be involved with, for instance education, environment, and housing. 
Participation can make the young people able to engage with issues of their choice, and to engage actively without the preset adult agencies. (Checkoway, 2011.) According to Michels and De Graaf (2010), it is crucial to enable citizens to participate in various societal processes and decision making to improve democracy. Stolle \& Hooghe (2011: 120) summarize the changes in participation affiliated with the past decades "...citizens today, especially younger generations, seem to prefer participating in the extraparliamentary realm, in non-hierarchical and informal networks, and in a variety of sporadic campaigns that are not institutionalized."

Although youth participation and gaming have been studied extensively, it seems that the number of studies on the relationship of different kinds of digital gaming habits and participation is very limited. The public discourse related to gaming is controversial, and gaming is sometimes affiliated with social hardship (e.g. Przybylski 2014). In this study, our goal was to understand youth's perceptions and motivations for digital and non-digital participation. We also elucidate how participation and societal satisfaction could differ between frequent and less frequent young gamers, and young people who play different genres of digital games. As a practical contribution, we also propose design implications for digital services that aim at motivating youth to participate in societal discussion.

\section{Background and Related Work}

\subsection{Youth's Digital and Non-digital Societal Participation}

According to Meriläinen et al. (2018), digital participation can be for instance reading blogs and answering digital surveys. Sæbø et al. (2008) assert that eParticipation activities can include but is not necessarily limited to voting, taking part in political discourse, and decision-making. In this paper, we use the concept of digital participation to denote a wide spectre of participational activities, similar to what Meriläinen et al. (2018) define digital participation to be. In Figure 1, we have described how participation, digital participation and eParticipation relate to each other in the context of this paper. Pessala (2009) arguments that the otherwise politically passive young people are primarily interested in political activities that happen online, which might play a key factor to succeed in enhancing active participation and citizenship. 


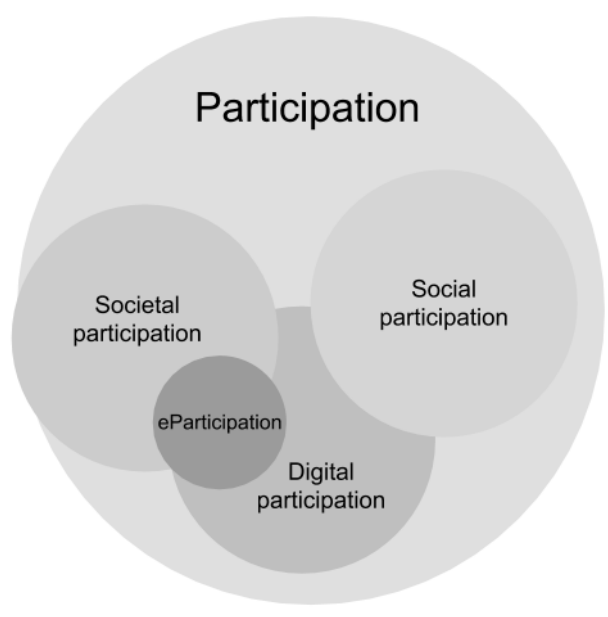

Fig. 1. Relationships of participation, digital participation and eParticipation in the context of this paper.

eParticipation or electronic participation denotes a form of participation in which information and communication technology is applied. eParticipation can be used to address the participation of individual persons, groups or governmental policy-making parties. (Albrecht et al. 2008). Panopoulou et al. (2014: 195) refer to electronic participation as "...the use of information and communication technologies to enhance political participation and citizen engagement." Sæbø et al. (2008) state that eParticipation has an intrinsic goal in enhancing active citizenship by enabling wider accessibility and availability of ways of engagement allowing society and government to grow fairer and more efficient. It is further discussed that "e" in eParticipation refers to the use of information and communication technologies, especially the Internet. However, meaning of "participation" might vary and it can be used to refer to "taking part in communal discussion or activity, or in the sense of taking some role in decision making". On more general level, eParticipation can be associated ambiguously with political deliberation and decision-making, and can occur in formal or informal settings. (Sæbø et al. 2008).

According to Meriläinen et al. (2018), obstacles among youth for participating in digital settings include absence of interest, belief of lack of impact, inadequate communication between youths and officials, and having no knowledge of the channels to utilize. In a literature review, Ianniello et al. (2018) capsulize the key dimensions obstructing participation to be information inaccessibility, officials' attitudes, community representations, process designs, group dynamics, and collaboration quality. Ianniello et al. (2018) also summarize that to overcome these obstacles, longterm interaction, involving participants in research, diversity, participation institutionalization, allowing multiple participation methods, and clarifying rules and mechanics must among other solutions be addressed.

Digital participation can also be approached through addressing the relationship of the Internet and political participation. Polat (2005) dissects the Internet enabling 
participation in three different dimensions: The Internet providing information, the Internet functioning as a communication medium, and the Internet functioning as a virtual public sphere. Polat (2005) also criticizes the existing tendency to think that the Internet is a technology first and information sharing and communication enabling platform second, which might accentuate technological determinism in the affiliated discourse. Pessala (2009) states that digital participation can be seen as a wider way of engagement than just participation through political parties, and it can also be used when referring to electronic societal participation.

In this paper, we use "Societal participation" to denote the participation of an individual or a group of individuals in the processes of the society, such as voting or participating in decision making, or engaging in political discussions. According to Harris et al. (2010), societal participation can also mean for instance joining a political party. In the context of this paper, "Social participation" means the participation of an individual or a group in various social and interactive processes that can take place between two or more people. These processes include constructions such as for instance friendships and hobby or other group activities. Kowert et al. (2014) describe social participation to include e.g. experience of being a part of a group. "Social digital participation" is used in this paper to denote the manifestation of these social participation activities happening in digital realms, being for instance online friendships, chatting, or social gaming.

\subsection{Gaming and Digital Participation}

Similarly, as for instance in USA, the vast majority of the young people play digital games in Finland (Pelaajabarometri, 2018; Lenhart et al., 2008). As the nature of gaming is ubiquitous, studying the varying habits related to it might offer valuable insight on how to model successfully possible elements in systems that aim to enhance youth participation. Lenhart et al. (2008) state that gaming is a comprehensive phenomenon that is relevant to the lives of majority of the youth despite of for instance socioeconomic status. It is also articulated that online gaming poses a key role in young people's social interactions.

The study conducted by Lenhart et al. did not exhibit a connection between the amount of gaming and the participation in civic or political activity of youth. Furthermore, it is said that there might be differences in engagement in political activity between those who play with others in physically same space and those who play with others only online. These activities include getting information on politics, participating in charity, being committed to civic participation, and persuading others to vote in election. In addition, the meta activities related to gaming, that can be for instance participating in game related discussions online and engaging in activities in gaming communities, are linked to higher civic and political engagement. (Lenhart et al. 2008). Ferguson \& Garza (2011), state that online social activity could be higher among those who play action games, but gaming is not linked to civic engagement in either way. However, their finding suggest that among action game players the parent's involvement can have a positive effect in the gaming youth's civic participation, whereas similar effects were not present in the non-gaming youth. It is further discussed 
that the multiplayer dimension with shared goals may contribute to the positive outcomes of gaming (Ferguson \& Garza, 2011). Lenhart et al. (2008) established no link between civic activities or attitudes and gaming. Still, the teens that had played games that offer social experiences like helping other players, learning about societal problems, and facing moral or ethical dilemmas reflected significantly higher civic engagement than those, who did not have such experiences. These activities included raising money for charity, getting information on politics online, and participating in protests.

\section{$3 \quad$ Studying the Gaming Youth's Digital and Non-digital Participation}

This study is part of a multidisciplinary research project exploring the capacities of young people (aged between 16 and 25) and the obstacles that hamper their engagement with society. This study is one of the several studies aiming to understand the perceptions and motivations of youth in relation to digital participation. One of the focus areas of the research project is in supporting the design of digital services that can motivate youth taking part in societal activities on different levels, from local to national level participation. The gaming youth are an interesting group to study since they are active in digital surroundings and may have specific motivations for societal participation.

The following research questions were formed:

RQ1: What kind of perceptions (e.g. definitions, and positive and negative aspects) do the gaming youth have about digital participation?

RQ2: What kind of obstacles and motivations do the gaming youth have for societal participation?

RQ3: How do types of digital and non-digital participation vary among different kinds of gamers?

3A: Are there differences in societal participation or digital or non-digital social participation between frequent and less frequent gamers?

3B: Are there differences in societal participation or digital or non-digital social participation between game genres played?

3C: Are there differences in personal life and societal satisfaction between frequent and less frequent gamers?

\subsection{Participants}

Data was gathered with a questionnaire and interviews (see chapter 3.2). Altogether 277 people answered the questionnaire. Participant age varied between 16 and 25 years, mean and median age being 20 years. Roughly, a third of the participants were under eighteen years of age. Three quarters of participants reported their gender to be male (n $=206)$, one fifth identified as female $(\mathrm{n}=58)$ and 12 participants identified as other or did not want to disclose their gender. 
According to the Finnish gamer barometer (Pelaajabarometri 2018), almost all of the Finnish people aged between 10 and 75 years play games generally. Digital games are played by more than two thirds. It is also asserted that $97 \%$ of $10-19$-year-olds and $91 \%$ of 20-29-year-olds play digital games more frequently than weekly. Barometer states that, $1 / 3$ play daily and $2 / 3$ play weekly, but in this study, $2 / 3$ of the respondents play daily and $2 / 3$ play weekly. In this study, the respondent's gaming is more frequent than in national barometer on average (Figure 2).

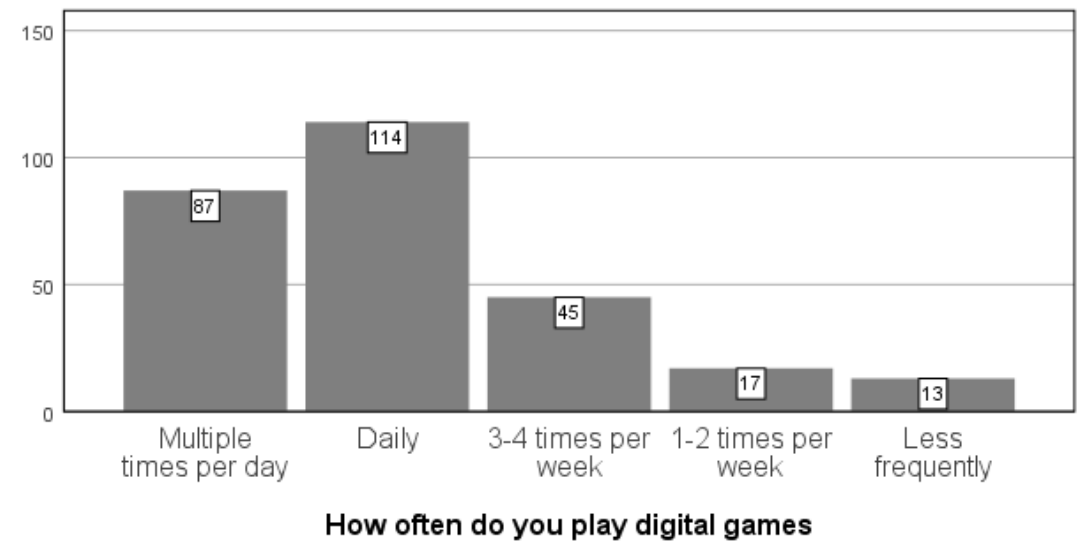

Fig. 2. Respondents' gaming frequency.

In total 25 people participated the interviews. Age of the participants ranged between 16-25 years (average 20.4 years, with standard deviation 3.5 years). Sixteen were male, 8 female and one identified as other. From the participants, 16 were studying full-time, 6 were working part-time or full-time and 3 were unemployed. The level of education ranged from 9 primary school students to 7 vocational school students, 7 high school graduates and one with a university degree. All participants were familiar with gaming culture and games in general. Only one person (ID19) was not actively playing games as a hobby at the time of the study.

\subsection{Procedure}

Data was acquired at the Assembly 2018. Assembly is an event about digital culture and arts, electronic gaming, and meeting old and new friends. Assembly is organized at the Expo and Convention Centre of Helsinki, located in Helsinki, the capital city of Finland. Over 5000 friends of digital arts and culture, demoscene, and gaming attend assembly every year. Most of Assembly visitors are of suitable age (From 16 to 25 years), and presumably active users of various digital services thus offering a plausible venue for conducting the study. Assembly 2018 was organized during 2.-5.8.2018.

Participants were able to answer the questionnaire both online and offline. The online version was executed on Webropol survey tool and could be taken at any suitable time during the event on participants' own device. The participation link was 
distributed to the event visitors through event website and on the event Facebook page. The questionnaire link and a small commercial of the research project was visible on info screen in the main hall. Mobile devices were supported by the online questionnaire. Researchers administered offline version during daytime on paper. Paper questionnaires were answered on-site next to the project's stand. All the participants were able to take part in lottery to win gift cards, regardless of the medium. In addition, participants were offered sweets at the stand after answering the questionnaire.

In addition to the questionnaire, interviews were conducted with the youth participating the Assembly event. People walking past or stopping by the stand were actively invited to take part to the interviews. At the beginning of the interview, participant answered a short background questionnaire on a paper. The interview sessions were audio recorded and varied from 17 to 69 minutes, with most interviews taking half an hour. After the session, participant was awarded with a movie ticket.

\subsection{Instruments}

A questionnaire and interview aimed for youth (age 16-25) were prepared in order to study the research questions. Questionnaire consisted of 11 main questions and had seven additional open-ended questions. Paper version of the questionnaire was laid on 11 pages. Five of the main questions were Likert scale questions consisting of 5-10 claims that were to be assessed on a scale of 1-7, 1 being "Fully disagree" and 7 being "Fully agree". Eighth option on the scale represented answer "I do not know or do not want to say / Does not apply to me". Lastly, also the background variables were inquired with optional participation to lottery. Participants were additionally able to give feedback on the questionnaire by assessing suitability of questionnaire length and how interesting the questions were. Background questions consisted of age, gender, nature of living area, postal number, province, marital status, employment status, and educational level. Main questions concerned the amount and frequency of playing digital games, gaming platforms and genres, ICT skills, societal participation, society and personal life satisfaction, social relationships, digital social participation, social gaming, and online relationships. Open-ended questions inquired news consumption habits, obstacles for participation, desires to legislative changes, and future dreams and aspirations. Formed sum variables and questions are described more specifically in Table 1.

A semi-structured interview was prepared to study youths' perceptions regarding different topics. Interview themes included societal and digital participation, gaming culture, future plans and dreams, future technology trends, and legislation. In this paper, the focus is in the results related to the themes of societal and digital participation. In the questions related to the societal participation, participants were asked how they have previously participated in political discussions, societies/clubs/associations, voluntary work, or other activities related to their living environment or society. These questions were followed by asking about the reasons for not participating and factors that motivate or could motivate participation in these activities. Next were the questions related to digital participation. Participants were asked to define "digital participation" and if they had utilized digital services to participate in the previously discussed societal 
activities. Finally, the positive and negative aspects of digital participation were discussed.

In summary, data used in this study consists of 277 respondents in questionnaire that consists of 18 questions and background questions and interviews of 25 participants with two interview themes included in the study.

Table 1. All the sub variables and formed sum variables presented with their Cronbach's alphas. * Ylilauta is a Finnish image and conversation board (http://www.ylilauta.fi)

\begin{tabular}{|c|c|c|c|c|}
\hline Sum Variable & Social Participation & $\begin{array}{l}\text { Digital Social } \\
\text { Participation }\end{array}$ & $\begin{array}{l}\text { Personal life } \\
\text { satisfaction }\end{array}$ & Societal participation \\
\hline Variable 1 & $\begin{array}{l}\text { I constantly feel } \\
\text { myself lonely } \\
\text { (REVERSED) }\end{array}$ & $\begin{array}{l}\text { Online gaming has a } \\
\text { significant role in my } \\
\text { friend relationships }\end{array}$ & $\begin{array}{l}\text { I am satisfied with } \\
\text { my life as it is }\end{array}$ & $\begin{array}{l}\text { I discuss timely domestic or } \\
\text { foreign events with my friends } \\
\text { or family often }\end{array}$ \\
\hline Variable 2 & $\begin{array}{l}\text { I enjoy other people's } \\
\text { company }\end{array}$ & $\begin{array}{l}\text { A significant part of } \\
\text { my social interactions } \\
\text { happen online (for } \\
\text { instance in games, } \\
\text { social media or chats) }\end{array}$ & $\begin{array}{l}\text { I am satisfied with } \\
\text { my work / studies / } \\
\text { other professional } \\
\text { status }\end{array}$ & $\begin{array}{l}\text { Under 18: I would vote in the } \\
\text { next election if i could / Over } \\
\text { 18: I will vote in the next } \\
\text { election }\end{array}$ \\
\hline Variable 3 & $\begin{array}{l}\text { I feel like I am a } \\
\text { relative part of some } \\
\text { group or team }\end{array}$ & $\begin{array}{l}\text { I produce content in } \\
\text { image boards or } \\
\text { message boards (Like } \\
\text { for instance Ylilauta* } \\
\text { or 4chan, for instance } \\
\text { text or images) }\end{array}$ & $\begin{array}{l}\text { I have good daily } \\
\text { routines }\end{array}$ & $\begin{array}{l}\text { I feel like I would succeed well } \\
\text { if I were to rationalize and } \\
\text { discuss my views on some } \\
\text { controversial political or } \\
\text { societal question }\end{array}$ \\
\hline Variable 4 & $\begin{array}{l}\text { I believe that others } \\
\text { enjoy my company }\end{array}$ & $\begin{array}{l}\text { I read / watch content } \\
\text { on image boards or } \\
\text { message boards (Like } \\
\text { for instance Ylilauta or } \\
4 \text { chan) }\end{array}$ & $\begin{array}{l}\text { I am satisfied with } \\
\text { my free time }\end{array}$ & $\begin{array}{l}\text { It is easy for me to find a } \\
\text { suitable political party }\end{array}$ \\
\hline Variable 5 & $\begin{array}{l}\text { I like doing things with } \\
\text { others }\end{array}$ & & & I am interested in politics \\
\hline Variable 6 & I have good friends & & & $\begin{array}{l}\text { I read / watch the news to get } \\
\text { information on timely events }\end{array}$ \\
\hline Variable 7 & I get new friends easily & & & \\
\hline $\begin{array}{l}\text { Number of } \\
\text { items }\end{array}$ & 7 & 4 & 4 & 6 \\
\hline $\begin{array}{l}\text { Cronbach's } \\
\text { Alpha }\end{array}$ & .88 & .70 & .82 & .81 \\
\hline $\begin{array}{l}\text { Distribution is } \\
\text { normal }\end{array}$ & No & Yes & No & No \\
\hline
\end{tabular}

\subsection{Analysis}

Overall sampling size is 277 after removing inappropriate subjects. For analysis of quantitative data, threshold for statistical significance alpha value of .05 was selected. A Python script was written to execute the two-tailed Mann-Whitney-U test on a set of multiple dichotomous variables.

Running a factor analysis for test variables was considered appropriate as KMO test value was .787 and Bartlett's test of sphericity produced a significant value $(p<.001$, $\mathrm{df}=210$ ). After addressing the Scree plot, maximum quantity of components was set 
to four. Principal component analysis was chosen as extraction method and rotation was done with Varimax. Factor loadings for each observed variable are represented in Table 2. Values under .300 were excluded from the table for clarity. Factor analysis results suggest a rather clear positioning of the observed variables in the four distinct components. However, some of the variables under the construct "Social participation" seem to contribute also to construct "Personal life satisfaction".

Table 2. Loading and cross-loading values for each observed variable in four factors

\begin{tabular}{|c|c|c|c|c|}
\hline & \multicolumn{4}{|c|}{ Loading in each factor } \\
\hline Observed variable & 1 & 2 & 3 & 4 \\
\hline I enjoy other people's company & 0.783 & & & \\
\hline I like doing things with others & 0.761 & & & \\
\hline I believe that others enjoy my company & 0.725 & & 0.340 & \\
\hline I have good friends & 0.724 & & & \\
\hline I get new friends easily & 0.719 & & & \\
\hline I feel like I am a relative part of some group or team & 0.636 & & 0.378 & \\
\hline I constantly feel myself lonely REVERSED & 0.467 & & 0.399 & \\
\hline I am interested in politics & & 0.823 & & \\
\hline $\begin{array}{l}\text { I feel like I would succeed well if I were to rationalize and discuss my views on } \\
\text { some controversial political or societal question }\end{array}$ & & 0.792 & & \\
\hline I often discuss with my friends and family the current events abroad or in Finland & & 0.790 & & \\
\hline I read / watch the news to get information on current events & & 0.630 & & \\
\hline $\begin{array}{l}\text { Under 18-yo: I would vote in the next election if I was eligible / Over 18-yo: I } \\
\text { will vote in the next election }\end{array}$ & & 0.609 & & \\
\hline It is easy for me to find a suitable political party & & 0.506 & & \\
\hline I am satisfied with my life as it is & & & 0.845 & \\
\hline I am satisfied with my work / study / other professional status & & & 0.830 & \\
\hline I am satisfied with my free time & & & 0.807 & \\
\hline I have good daily routines & & & 0.590 & \\
\hline $\begin{array}{l}\text { A significant part of my social interactions happen online (for instance in games, } \\
\text { social media or chats }\end{array}$ & & & & 0.835 \\
\hline Online gaming has a significant role in my friend relationships & & & & 0.764 \\
\hline $\begin{array}{l}\text { I read / watch content on image boards or message boards (Like for instance } \\
\text { Ylilauta or } 4 \text { chan }\end{array}$ & & & & 0.692 \\
\hline $\begin{array}{l}\text { I produce content in image boards or message boards (Like for instance Ylilauta } \\
\text { or } 4 \text { chan, for instance text of images }\end{array}$ & & & & 0.617 \\
\hline
\end{tabular}

Questions related sum variables were created and can be seen in Table 1. All sum variables except one received more than $\alpha=.70$ as their Cronbach's alpha value reflecting an acceptable or good inner consistency. Additionally, the sub variables were inspected in a cross-correlation matrix. Sum variables were tested for their distribution normality with Kolmogorov-Smirnov and Shapiro-Wilk tests and the distributions were also visually assessed. The used tests are explained in more detail along with the results.

Interviews were transcribed and qualitatively analyzed by categorizing similar responses to categories that were derived from the data. Similar categorization process was followed with the open questions of the questionnaire. 


\section{$4 \quad$ Results}

\subsection{RQ1: What kind of perceptions do the gaming youth have about digital participation?}

How did the interview participants define "digital participation"? The most often mentioned aspect (11/25 respondents, $44 \%)$ when defining digital participation related to utilizing social media services, such as Facebook, Twitter or WhatsApp. Six respondents $(24 \%)$ considered that digital participation includes active participation in discussions (e.g. Slack) or discussion forums in the Internet (e.g. Reddit, 4chan). For instance, one respondent (ID9) commented that digital participation is "something more clever than evening paper's comment section. I don't consider that yet as digital participation, but taking part in discussion forums. I am mainly in Slack and some hobby-specific subreddit. Maybe 4chan is counted [as digital participation], maybe not". Four participants (16\%) emphasized the creation of digital content in the Internet, such as videos, graphics and texts as a way of participation. Three mentions (12\%) related to answering or creating own digital surveys and two people mentioned commenting or liking existing content as a way of participation. Rest of the individual comments related to citizen's initiatives in the Internet, voting (in web), web courses for teaching, taking part in software development, and "doing something together in different locations" e.g. charity.

When asked about the positive aspects of digital participation, the following topics were brought up: 1) low threshold for participation because you can do it on your own time, from any location (e.g. from a bus in countryside) and it suits for anyone (e.g. introvert personality, people with disabilities), 2) sharing information and reaching people is easy and fast, 3) organizing e.g. events via digital channels is cheap and easy, and 4) the freedom of expression. Negative aspects in relation to digital participation included the following: 1) lack of commitment as it is easy to ignore or change one's mind about participation e.g. in event, 2) anonymity leads more easily to aggression, harassment and unfriendly behavior, 3) misinformation and provocation ("trolling"), 4) misuse, cheating and hijacking (e.g. Twitter hashtag), and 5) technical issues (e.g. poor Internet connection or web-cam).

\subsection{RQ2: What kind of obstacles and motivations do the gaming youth have for societal participation?}

The questionnaire results $(\mathrm{N}=217)$ regarding the sum variable Societal participation (scale 1-7, 6 items, see Table 1) suggest that the gaming youth perceive themselves as slightly more towards active in societal participation (Mean $=4.64, \mathrm{SD}=1.29$ ).

In the interviews $(\mathrm{N}=25)$, participants were asked how they have previously participated in political discussions, societies/clubs/associations (e.g. nongovernmental organizations), voluntary work, or other activities related to their living environment or society. First, regarding politics, 12 out of 25 participants tend to discuss politics, some rarely and others more actively, with their family or friends, but 10 of them not in any public channel. News from politics are followed with varying 
interest, mainly from digital newspapers and social media sites (7 respondents), such as Facebook and Reddit. Few examples of different political activities were brought up: one respondent had participated in protest marches and one had signed a petition. In school context, two people had participated in student council and one in a "parliament club". From digital participation perspective, examples from individual respondents included 1) answering digital surveys about political parties (ID12) or life in the city (ID19), 2) sharing references to information sources in social media discussions (ID8), 3) discussing political topics during live video stream (ID8) or creating political videos (ID6) in YouTube, and 4) participating in Slack discussions for preparing a feedback for a legislative proposal from European Aviation Safety Agency (ID9).

Next, the results concerning obstacles for gaming youths' participation in societal/political discussions are presented. This topic was included in both the questionnaire and interviews. Figure 3 presents the questionnaire results, illustrating the main reasons that gaming youth propose for not taking part in societal discussions.

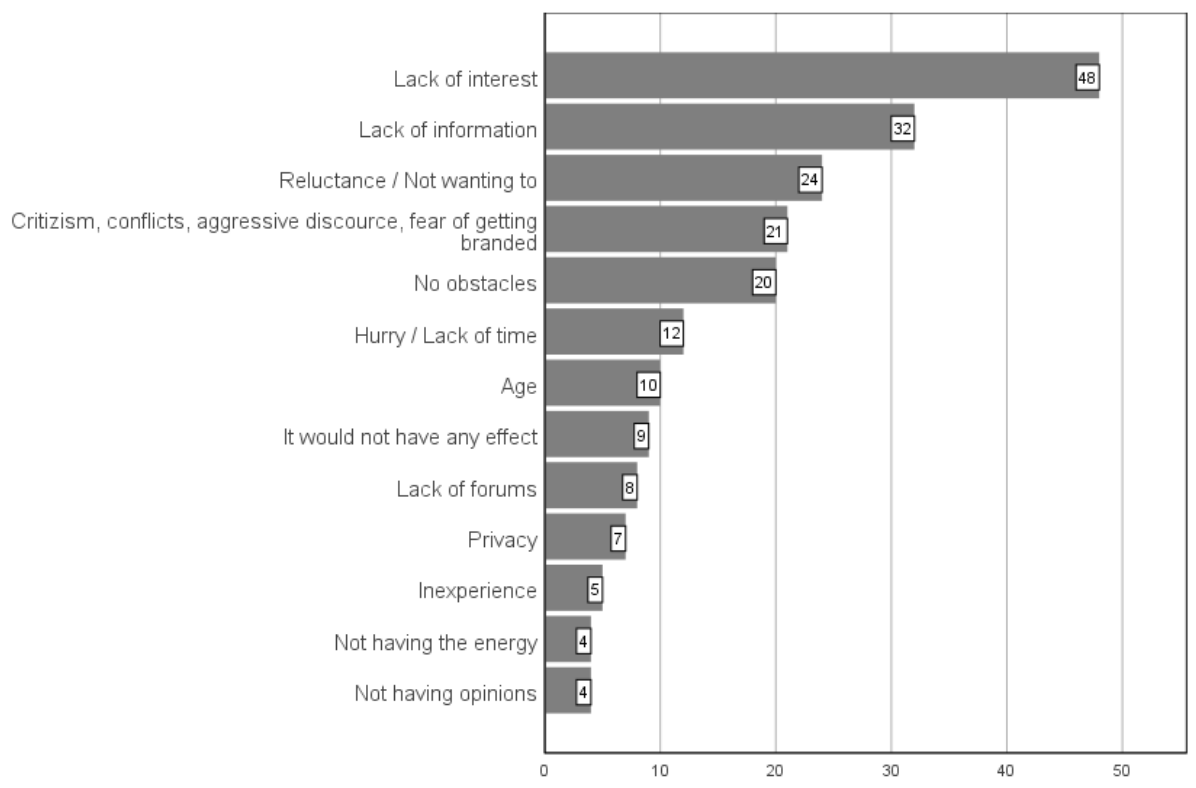

Fig. 3. Categorization of the questionnaire responses to the open question "Reasons that prevent me from taking part in societal discussions are..." The following single responses were also received: unspecific fear, religion, poverty, language barriers, and ethnic background. $(\mathrm{N}=277)$.

The interview results are in line with the questionnaire results, suggesting that the main reasons for youth not being more active in political discussions are 1) lack of interest (7 out of 25 responses), 2) conflicts, aggressive discourse (5), 3) lack of information $(3), 4)$ not a suitable life situation due the young age (3), and one of each of the following: it would not have any effect, no opportunities to have an impact, lack of 
political discourse in family or with people around you, badly moderated discussion forums, things happen too slowly, and "all that you put in the Internet stays there".

What would motivate youth to take part in political discussions? This was asked in the interviews. The motivational factors included the following: 1) topics relevant for oneself or one's own life (e.g. student life, sexual minorities, the environment, morally meaningful choices) (4 responses out of 25), 2) topics that are interesting (e.g. political science, technology, games) (3), 3) desire to share your opinion (e.g. in contrast to your friend's opinion, because of your own persona, or in order to provide facts to the discussion) (3), 4) visible results from your activity in the community or in relation to your goal (2), and one of each of the following motivational aspects: friends' activity and opinions, clearly presented information aimed for young people, meeting politically active youth such as youth parliament representatives, supporting candidates with similar interests, opinions that strongly differ from yours, restricting your rights, acknowledging individuals when evaluating impacts of decisions, and safe environment for youth to present their opinions.

\subsection{RQ3: How do types of digital and non-digital participation vary among different kinds of gamers?}

3A: Are there differences in societal participation or digital or non-digital social participation between frequent and less frequent gamers?

Results shown in Table 3 and Figure 4 suggest that people who play more often might be more active also in other social digital activities. Running a Kruskal-Wallis test on variables "Social participation" $\left(\chi^{2}(4)=.78, p=.94\right)$ and "Societal participation" $\left(\chi^{2}\right.$ $(4)=4.74, p=.32$ ) in classes of gaming frequency did not exhibit a statistically significant difference. However, a statistically significant difference was found in variable "Digital social participation" in categories of gaming frequency when testing with one-way ANOVA $[\mathrm{F}(4,258)=7.05, p<.01]$. Post-hoc comparison using the Tukey HSD test revealed multiple differences between groups indicating increased values in variable "Digital social participation" among categories of more frequent gamers than categories of less frequent gamers. In Table 3, the statistically significant differences are described in more detail, each category mean is displayed and significance values $(p)$ of differences between categories are presented.

Table 3. Statistically significant differences in variable "Digital social participation" between categories of gaming frequencies. In addition, category means and significance $p$ value of each difference are displayed.

\begin{tabular}{|l|l|l|l|l|}
\hline Category & Mean & Category & Mean & $\boldsymbol{p}$ \\
\hline Multiple times per day & 4.46 & $3-4$ times per week & 3.69 & .02 \\
\hline Multiple times per day & 4.46 & $1-2$ times per week & 3.35 & .03 \\
\hline Multiple times per day & 4.46 & Less frequently & 2.60 & $<.01$ \\
\hline Daily & 3.96 & Less frequently & 2.60 & .01 \\
\hline
\end{tabular}




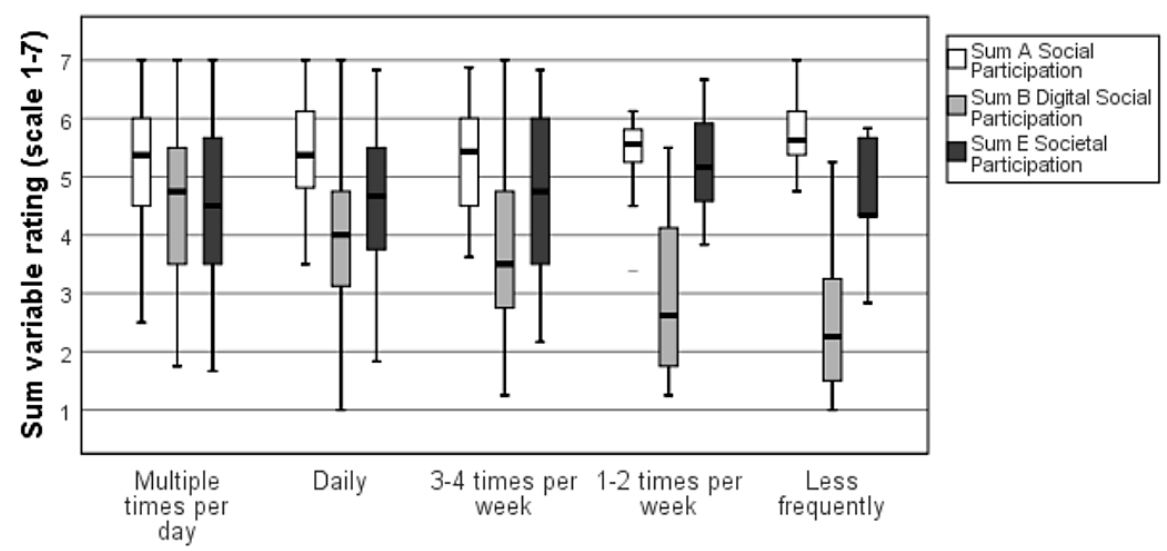

How often do you play digital games

Fig. 4. People who play more often, might be more active in other digital social settings also - a statistically significant difference was found for instance between categories "Multiple times per day" and "3-4 times per week" in variable "Digital Social Participation"

\section{B: Are there differences in societal participation or digital or non-digital social participation between game genres played?}

Multiple statistically significant differences between whether a certain genre is played or not were found in various sum variables. For instance, the results assert that respondents that reportedly play strategy games would be more likely to participate in societal activities $(\mathrm{U}=4178, p<.01)$. This difference is presented in Figure 5.

In the light of effect sizes, especially the difference between those who play shooter games and those who do not in the variable "Digital Social Participation" is exceptionally noticeable $(d=.81)$, and the difference between those who play strategy games and those who do not in variable "Societal participation" $(d=.45)$ as these effect sizes can be considered large and medium respectively.

In Table 4, all the statistically significant differences in corresponding dependent variables between playing or not playing a specific genre are displayed with both categories medians, Mann-Whitney-U values and $p$-values. Also, effect sizes are displayed in the table. Rest of the effect sizes remain small, however none of the effects of statistically significant differences between categories of playing or not playing distinct genres should be considered trivial or non-existent. Genre "Shooters" should be approached with care, because the number of those who did not reportedly play this genre, is only 28 . For instance, strategy gaming genre on the other hand represents a good balance between those who play or do not play games that belong to this genre (Yes: 133, No: 84). Number of observational units in each genre under each category are also displayed in the table under column "Played Y/N". 


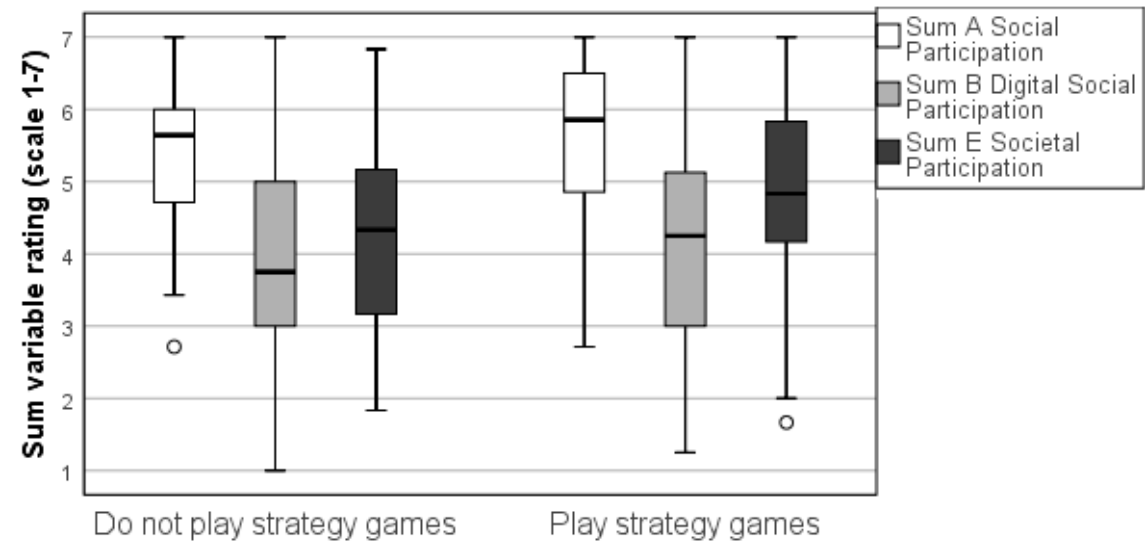

Gaming genre: Strategy games

Fig. 5. A statistically significant difference between those who play strategy games and do not play strategy games was found in sum variables "Digital Social Participation" and "Societal Participation", indicating that strategy game players might be more prone to societal activities.

Table 4. Statistically significant differences in sum variables between categories of playing or not playing a certain gaming genre

\begin{tabular}{|l|l|c|c|c|c|c|c|}
\hline Gaming genre & $\begin{array}{l}\text { Sum variable a difference } \\
\text { was found in }\end{array}$ & $\begin{array}{l}\text { Median } \\
\text { Yes }\end{array}$ & $\begin{array}{l}\text { Median } \\
\text { No }\end{array}$ & $\begin{array}{l}\text { Played } \\
\text { Y/N }\end{array}$ & $\boldsymbol{U}$ & $\boldsymbol{p}$ & $\begin{array}{l}\text { Effect } \\
\text { size }(\boldsymbol{d})\end{array}$ \\
\hline Puzzles and Card games & Societal Participation & 5.00 & 4.50 & $63 / 154$ & 3900 & .02 & 0.34 \\
\hline Shooters & Social Participation & 5.71 & 6.14 & $235 / 27$ & 4135 & .01 & 0.41 \\
\hline Shooters & Digital Social Participation & 4.00 & 3.25 & $236 / 28$ & 1939 & $<.01$ & 0.81 \\
\hline Strategy & Societal Participation & 4.83 & 4.33 & $133 / 84$ & 4178 & $<.01$ & 0.45 \\
\hline Action & Digital Social Participation & 4.00 & 3.75 & $152 / 112$ & 7144 & .03 & 0.29 \\
\hline Simulation & Societal Participation & 5.00 & 4.50 & $76 / 141$ & 4221 & .01 & 0.40 \\
\hline Multiplayer Online & Digital Social Participation & 4.00 & 3.75 & $157 / 107$ & 7004 & .02 & 0.32 \\
\hline Multiplayer Online & Societal Participation & 4.67 & 4.33 & $124 / 93$ & 4800 & .03 & 0.31 \\
\hline Roleplaying & Digital Social Participation & 4.25 & 3.75 & $101 / 163$ & 6489 & $<.01$ & 0.36 \\
\hline Roleplaying & Societal Participation & 5.00 & 4.33 & $84 / 133$ & 4404 & .01 & 0.37 \\
\hline Online roleplaying & Digital social participation & 4.25 & 3.75 & $57 / 207$ & 4836 & .04 & 0.33 \\
\hline
\end{tabular}

3C: Are there differences in personal life and societal satisfaction between frequent and less frequent gamers?

The study results suggests that the people who play multiple times per day are less satisfied with the Finnish society than those who play only daily. Executing the Kruskal-Wallis test on variable "Personal Life Satisfaction" in categories of gaming 
frequency variable did not show a statistically significant difference $\left(\chi^{2}(4, \mathrm{~N}=267)=\right.$ $1.99, p=.74)$. However, a statistically significant difference was detected in the sum variable "Finnish Society Satisfaction" when comparing categories of gaming frequency $\left(\chi^{2}(4, \mathrm{~N}=206)=13.66, p<.01\right)$. Running a Dunn's post-hoc test reveals a statistically significant difference between categories of gaming frequency "Multiple times per day" and "Daily" $\left(\chi^{2}(4,206)=13.66, p=.02\right)$. No other statistically significant differences were found between categories.

\section{Discussion}

The activities that the interviewed youth affiliate with digital participation were mainly related to social media use, activity in discussion forums, creating digital content and answering digital surveys. Similar activities were suggested in Meriläinen et al. (2018). Only a few described activities related to digital participation were related to eParticipation activities as described by Sæbø et al. (2008). These included voting and starting citizen's initiatives in the Internet, as a way of taking part in political discussions or decision making that are some of the key aspects of eParticipation. Furthermore, the array of obstacles for youth participation in digital setting found in this study is analogous to the proposed obstacles by Meriläinen et al. (2018). However, this study suggests some additional obstacles, in specific fear of conflicts and young age, although the latter can relate to the belief of lack of impact.

Also, the results related to gaming and its relationship to participation are mostly coincident with the research executed by Lenhart et al. (2008), as for instance the digital social activities show higher rating among those who play action games compared to those who do not play action games. Similarly, no statistically significant difference was found in societal participation between more or less frequent players. The difference between people who play or do not play a game of certain genre in the variables "Social Participation" and "Societal Participation" could be affiliated with the contents and mechanics of the games. Lenhart et al. (2008) assert that playing games that include social experiences, helping others, and facing moral dilemmas, can be linked to heightened civic engagement. The game genres that exhibit in this study these kinds of positive phenomena, do in some instances include the described activities: In strategy games, resource division problematics are addressed and multiplayer online games include social activities and helping others, and these indeed were, among others, the genres that showed positive effect in societal participation.

\subsection{Implications to the Design of Digital Services that Activate Youth to Societal Participation}

Based on the results of our study we propose the following initial design implications for digital services that aim at motivating youth to participate in societal discussion and other activities.

Providing safe environment for youth participation. The environment should be user-friendly and supportive towards newcomers, those interested but not yet familiar 
in political debate. Many young people are afraid of conflicts and discussions about sensitive topics such as immigrants. Therefore, discussion area should include clear rules and be well moderated in order to prevent inappropriate behavior, such as personal insults and harassment. In addition, it could be emphasized that the they are not too young to participate.

Offering information that entices participation. Lack of grounding information was one of the main obstacles for participation. There should be sufficient depth of background information about the topics to enable insightful discussion. The service should offer easy access and means for finding areas of own interest (e.g. tags, favorites, recommendations). Furthermore, the subject matters should be presented in an interesting way, targeted at the youth - for example, in a visual way, instead of long textual descriptions. Possibilities of applying information representation conventions from games should be considered in for instance showing societal objectives, progress, and resources.

Matching digital participation to personal needs. Youth's interest to participate in societal discussions varies greatly. Participation should be enabled on different "requirements levels", for example for users who can spare little time and effort, and for people who have more motivation to dig deeper into the topics. The digital service could offer match making between youth of similar "spirit" - and at the same time avoiding users staying solely in the circles ("bubbles") of like-minded people.

Rewarding participation. The users should be able to see the results of their own activities easily and concretely, e.g. through visual indicators. The system could provide the users with some kind of digital or even physical reward. Digital rewards, such as badges, could be posted within the same service but also in users' other social media services - naturally only with the user's permission.

\subsection{Study Limitations}

Although the study has been conducted with great regard to data acquisition, handling, analysis, and reporting, some limitations need to be mentioned. The questionnaire question sets have not been validated in a large-scale study and thus the indicators can be limited in their reliability, however they were applied and combined from several credible studies, and reviewed by three researchers. In addition, the results of the conducted factor analysis further reflect sum variable validity. In addition, the inner consistency was considered high in all the sum variables that exhibited statistically significant discrepancies, which can reflect instrument reliability. The sum variable "Digital Social Participation" had a $1 / 4$ of its value from online gaming and thus might be biased, as respondents were mostly active gamers. It also must be mentioned that the results are generalizable only in a certain section of Finnish youth, as for instance gaming amount related variables differ from the national equivalent. Considering the abovementioned limitations in instruments and analysis, the effect sizes are additionally addressed in relation to the results and sincerely described. Also, the Bonferroni (in which, the significance value is multiplied by each pairwise test in set) correction method is used in subsequent testing scenarios where applicable. Finally, the qualitative 
interview data were analyzed and categorized by a single researcher, while with multiple analyzers there could have been some differences in the final categorization.

\subsection{Future Work}

In our future work we are conducting field studies of the youth's participation behavior. Furthermore, we will do design research on how, using participatory design methods, various youth groups could be motivated to digital societal participation. One of the approaches used in the human-centered design of novel digital services is gamification, which is a promising approach for digital service design (e.g. Deterding et al., 2011; da Rocha Seixas et al. 2016; Gabarron et al. 2013). This approach is expected to be valuable for both gaming and non-gaming youth, and it may give rise to novel forms of participation. In the coming two years, we will design and implement digital service prototypes and utilize them in actual youth participation tasks such as city planning, work mentoring and commenting of legislative proposals.

\section{Conclusions}

This study produced relevant information on the societal and social activities and tendencies exhibited by the gaming youth. In specific, the findings point out that there are several obstacles for societal participation but also a multitude of motivators that can be used to understand requirements for design for societal inclusion. The findings shed light to the phenomenon of youth participation as part of the development of inclusive society. The proposed design implications can be applied when designing digital services for the youth. The findings contribute to the field of HCI by providing insights of youth's needs and motivations to use digital services for societal participation. The suggested design implications can give guidance for developers of digital services for youth participation. Designers should aim to remove the identified obstacles and support user motivation by providing safe environment for youth participation, offering information that entices participation, matching digital participation to personal needs, and by rewarding active participation.

\section{$7 \quad$ Acknowledgements}

We are grateful to the reviewers for their time and effort. We thank Niina Meriläinen, Eero Saukkonen, and Marika Hölttä for their support in data acquisition.

The research was funded by the Strategic Research Council at the Academy of Finland, project ALL-YOUTH with decision no 312689. 


\section{$8 \quad$ References}

1. Albrecht, S., Kohlrausch, N., Kubicek, H., Lippa, B., Märker, O., Trénel, M., Vorwerk, V., Westholm, H., Wiedwald, C. (2008). eParticipation - Electronic Participation of Citizens and the Business Community in eGovernment. Institut für Informationsmanagement Bremen GmbH (ifib).

2. Checkoway, B. (2011). What is youth participation? Children and Youth services review. Volume 33, issue 2. (340-345). https://doi.org/10.1016/j.childyouth.2010.09.017.

3. Da Rocha Seixas, L., Gomes, A. S., \& De Melo Filho, I. J. (2016). Effectiveness of gamification in the engagement of students. Computers in Human Behavior, 58, 48-63. doi:10.1016/j.chb.2015.11.021.

4. Deterding, S., Sicart, M., Nacke, L., O'Hara, K., \& Dixon, D. (2011). Gamification: using game-design elements in non-gaming contexts. In CHI'11 Extended Abstracts. On Human Factors in Computing Systems (2425-2428). ACM.

5. Dietlind Stolle \& Marc Hooghe (2011) SHIFTING INEQUALITIES, European Societies, $13: 1,119-142$.

6. Ferguson, C. J., \& Garza, A. (2011). Call of (civic) duty: Action games and civic behavior in a large sample of youth. Computers in Human Behavior, 27(2), 770-775. doi:10.1016/j.chb.2010.10.026.

7. Gabarron, E., Schopf, T., Serrano, J. A., Fernandez-Luque, L., \& Dorronzoro, E. (2013). Gamification strategy on prevention of STDs for youth doi:10.3233/978-1-61499-289-91066.

8. Harris, A., Wyn, J., \& Younes, S. (2010). Beyond apathetic or activist youth: 'ordinary' young people and contemporary forms of participation. Young, 18(1), 9-32.

9. Ianniello, M., Iacuzzi, S., Fedele, P., Brusati, L. (2018). Obstacles and Solutions on the Ladder of Citizen Participation: A Systematic Review. Public Management Review, Volume 21, 2019 Issue 1.

10. Isola, A-M., Kaartinen H., Leemann, L., Lääperi, R., Schneider, T., Valtari, S., Keto-Tokoi, A. (2017). Mitä osallisuus on? Osallisuuden viitekehystä rakentamassa. Terveyden ja hyvinvoinnin laitos. Juvenes Print - Suomen Yliopistopaino Oy.

11. Kowert, R., Domahidi, E., Festl, R., \& Quandt, T. (2014). Social gaming, lonely life? The impact of digital game play on adolescents' social circles. Computers in Human Behavior, 36, 385-390.

12. Lenhart, A., Kahne, J., Middaugh, E., Macgill, A.R., Evans, C., Vitak, J. (2008). Teens, Video Games, and Civics. Pew Internet \& American Life Project. 202-415-4500.

13. Meriläinen, N., Pietilä, I., Varsaluoma, J. (2018). Digital services and youth participation in processes of social change: World Café workshops in Finland. Presented at 2018 ECPR General Conference Universität Hamburg.

14. Michels, A., De Graaf, L. (2010). Examining Citizen Participation: Local Participatory Policy Making and Democracy. Local Government Studies. Volume 36, 2010 - Issue 4. Pages 477-491. https://doi.org/10.1080/03003930.2010.494101

15. Myrskylä, P. (2012). Hukassa - Keitä ovat syrjäytyneet nuoret? EVA Analyysi (Vol. 12, 1.2.2012).

16. Myrskylä, P. (2011). Young people outside the labour market and studies. Työ ja yrittäjyys 12/2011. Ministry of Employment and Economy.

17. Mäyrä, F., Karvinen, J., Ermi, L. (2018) Pelaajabarometri 2018: Monimuotoistuva Mobiilipelaaminen. TRIM Research Reports 28. Tampere: Tampereen yliopisto. http://urn.fi/URN:ISBN:978-952-03-0153-8. 
18. Panopoulou, E., Tambouris, E., \& Tarabanis, K. (2014). Success factors in designing eParticipation initiatives. Information and Organization, 24(4), 195-213. doi:10.1016/j.infoandorg.2014.08.001.

19. Pessala, H. (2009). Suomalaisten yhteiskunnallinen osallistuminen internetissä. Viestinnän tutkimuskeskus, CRC, Helsingin yliopisto, viestinnän laitos. Oikeusministeriön demokratiayksikkö.

20. Polat, R.K. (2005). The Internet and Political Participation: Exploring the Explanatory Links. European Journal of Communication 2005; 20; 435.

21. Przybylski, A. K. (2014). Electronic gaming psychosocial adjustment. Pediatrics, 134(3), e716-e722.

22. Sutela, E., Haapakorva, P., Marttila, M., Ristikari, T. (2018). Haavissa? Aktivointitoimissa olleiden nuorten taustat ja tilanteet toimien jälkeen. Vertailu Suomen kuuden suurimman kaupungin välillä Kansallinen syntymäkohortti 1987 -aineiston valossa. Terveyden ja hyvinvoinnin laitos (THL). Työpaperi 5/2018.

23. Sæbø, Ø., Rose, J., \& Skiftenes Flak, L. (2008). The shape of eParticipation: Characterizing an emerging research area. Government Information Quarterly, 25(3), 400-428. doi:10.1016/j.giq.2007.04.007. 